\title{
Stress during COVID-19 pandemic: mental health condition in Indonesia
}

\author{
Fransiska Kaligis, Madhyra Tri Indraswari, Raden Irawati Ismail
}

pISSN: 0853-1773 • elSSN: 2252-8083 https://doi.org/10.13181/mji.bc.204640 Med J Indones. 2020;29:436-41

Received: April 06, 2020

Accepted: July 24, 2020

Published online: October 09, 2020

Authors' affiliations:

Department of Psychiatry, Faculty of Medicine, Universitas Indonesia, Cipto Mangunkusumo Hospital, Jakarta, Indonesia

\section{Corresponding author:}

Fransiska Kaligis

Department of Psychiatry, Faculty of Medicine, Universitas Indonesia, Cipto

Mangunkusumo Hospital, Jalan Salemba

Raya No. 6, Central Jakarta 10430

Indonesia

Tel/Fax: +62-21-3106218/

+62-21-3106184

E-mail: kaligisfransiska@gmail.com/

fransiska.kaligis@ui.ac.id

\begin{abstract}
Pandemics have occurred throughout the decades. The last pandemic was the Spanish flu pandemic in 1918, which infected 500 million people and caused death to as many as 100 million people worldwide. At present, a similar situation is occurring as coronavirus disease 2019, caused by severe acute respiratory syndrome coronavirus 2, has infected a few million people worldwide and has been declared a pandemic by the World Health Organization in March 2020. There are various mental health responses in pandemic outbreaks. People's thought process, behavior, and emotional response to an outbreak vary greatly according to their own backgrounds and the community that they live in. For some people, the misinformation, uncertainty, and fear of contagion may increase stress and anxiety, which can induce mass panic. Mental health education and psychological support from all stakeholders, such as the government, health professionals, and the community, may be valuable during a pandemic.
\end{abstract}

KEYWORDS COVID-19, pandemic, panic, stress
Pandemics have occurred regularly throughout the decades. The last pandemic took place in 1918, the Spanish flu, infected 500 million people and caused death to as many as 100 million people worldwide. We are presently facing a similar situation as coronavirus disease 2019 (COVID-19), which is caused by severe acute respiratory syndrome coronavirus 2 , an outbreak that initially appeared in China in December 2019, has been declared a pandemic by the World Health Organization (WHO) on March, 2020.1 The impact of COVID-19 pandemic differs across countries. Developing countries with limited health resources are struggling to keep their citizens healthy amid the COVID-19 outbreak. In Indonesia, the first case was confirmed on March 2, 2020. On May 25, 2020, the number of people infected had risen to 22,750 with 1,391 deaths and 5,642 recovered from across 34 provinces. $^{2}$ As with the rest of the world, people in Indonesia are restless, worried, and angry. While this disease is killing many people worldwide by attacking the lungs and other feasible organs, it can also cause other health issues, such as mental illness. This article aimed to raise awareness about mental illness amid this pandemic in Indonesia.

\section{Stress and psychological responses during the COVID-19 pandemic}

The COVID-19 pandemic can be stressful for people. ${ }^{3}$ Overwhelming fear and anxiety toward the disease causes strong emotions to emerge out 
of adults and children of all ages. Healthy coping mechanisms in people toward stress will create a stronger society and communities. How an individual responds to an outbreak can vary greatly according to their own backgrounds and the community that they live in. Some populations may respond more strongly to the stress of a pandemic, which includes the elderly, those with chronic diseases who are at higher risk for COVID-19, children and teens, healthcare providers or first responders, and people who already have mental health conditions. ${ }^{3}$ Pre-existing mental health issues may worsen with the stress of a pandemic. Furthermore, the elderly, especially those with reduced cognitive function, might become more agitated and irritated under isolation conditions. In addition, children could feel fear and sadness because they cannot socialize and have to adjust to a new routine at home. ${ }^{3,4}$ The stress that people may experience during the pandemic can manifest as fear and worry about their health, changes in sleep and eating patterns, trouble sleeping and concentrating, worsening of chronic health problems, and increased intake of alcohol, smoking, or other substances. 4,5 The most common manifestation of stress is low mood and irritability. Though stress is a normal response during a crisis, stress is known to lower the host immune system and leads to immune dysregulation, which can decrease or worsen the host condition. ${ }^{6}$ During these pandemic, the sources of stress can result from following the death toll of the virus, frequently monitoring media or social media reports, feeling isolated during quarantine, not being able to be with loved ones, and experiencing financial hardship. Thus, mass quarantine is highly likely to increase anxiety or another mental health condition significantly. ${ }^{3}$

There are various psychological reactions in pandemic outbreaks. As mentioned above, some could experience anxiety, insomnia or hypersomnia, changes in eating patterns, or substance abuse. One example that happens most frequently during this situation is a mass panic. When we explore its development, it usually starts from misinformation from unreliable media. Fueled by uncertainty, it grows in the limbic system, explodes through media and public communication, and changes people's thoughts, behaviors, and emotional responses. ${ }^{1,7}$ If the panic response gets out of hand, it may overpower the coping resources of an individual, or even an entire community. This panic response arises from the psychological feeling of "fear of contagion," that includes fear of the virus is transmitting and the fear of getting infected at any time. ${ }^{1}$ This feeling may lead to mass panic. Just like how a mass panic mirrors a physical disease, a mental illness can also mimic an actual contagion. A high surge of information or news about COVID-19 will turn into widespread panic. Mass panic can be described as the outbreak of multiple but incomprehensible symptoms. ${ }^{1}$ The most common symptoms appear to be nausea, vomiting, headache, and dizziness or light-headedness. However, this condition is a rare response and usually only take place in situations involving real physical danger., Anxiety will cause more harm to someone physically, and it easily spreads within community. ${ }^{1}$ The president of Indonesia, Joko Widodo, tried to prevent this situation by filtering all of the information circulating about COVID-19. However, this action has received backlash, since the public assumed a lack of transparency on the government about the real COVID-19 situation in the country. ${ }^{8}$

Currently, WHO and other public health authorities around the world are employing substantial efforts to contain the COVID-19 outbreak and the stress generated by it. Together with the Inter-Agency Standing Committee, WHO has provided a briefing note that summarizes key mental health and psychosocial support considerations in relation to the COVID-19 pandemic. One point that they highlighted is that during a pandemic, it is common for individuals to feel stressed and worried. Thus, it is important to have good resilience and mental support during this situation. Furthermore, professional health workers have been tasked to prepare guidelines for dealing with mental health problems that would arise during the pandemic.8,9

It is also important to note that frontline workers such as doctors, nurses, and ambulance drivers, are exposed to additional stress during the COVID-19 pandemic. They have experienced stigmatization, higher demands during work, fear of spreading COVID-19 onto their families, not to mention the physical strain they have had to endure while using protective equipment and the physical isolation to which they have had to submit themselves in order to protect their families. ${ }^{10}$ This pandemic is mobilizing all available healthcare personnel across the country, placing them in high-pressure situations that call for making decisions without proper guidelines. It may 
cause some personnel to experience moral injury or mental health problems. Moral injury is not a mental illness, but it is a term used for psychological distress that ensues from an action or from the lack of it. ${ }^{11}$ Those who develop moral injury tend to blame themselves when something goes wrong, especially when faced with a challenge they feel unprepared for. In the uncertainty created by COVID-19, medical professionals need to prioritize patients and allocate resources according to the most urgent needs, since resources are limited. They also need to take care of their physical and mental health during these distressing times. Health professionals need to be prepared for the unexpected during this pandemic and avoid being overly stressed and overworked. They also need to be ready to leave their families for a while and to accept the fact of being at high risk of getting infected. ${ }^{11}$ As the situation progresses, medical workers might feel frustrated and let down by the hospital and government regulations, especially with the shortage of protective equipment. ${ }^{10,11}$ Continuous fear, worry, and stress during COVID-19 may lead to long-term psychological consequences within communities and families. Social networks, local dynamics, and economics deteriorate, and stigma toward surviving patients and relapses in patients with developing or existing mental health and substance use disorders ensue. People are also more likely to express their anger and aggression against government and frontline workers, even causing people to distrust the information from the government and other authorities. All these reactions may be based on realistic situations, but often, it also happens due to lack of knowledge, rumors, and misinformation that are spreading rapidly. ${ }^{10}$ The combination of the lack of knowledge and misinformation makes negative stigma inevitable and creates a huge burden for those who are affected. ${ }^{1}$ Stigma toward infected patients results in social avoidance or rejection. It can dispirit them, may prevent them from seeking medical care, and discourage them from adopting healthy behaviors. ${ }^{11}$ Since social stigma and discrimination due to COVID-19 are starting to get worse, it is important to take steps. Stigma is usually directed toward people who have been infected, their family members, as well as healthcare and other frontline workers. Specific care should also be done to promote the integration of people who have been infected. COVID-19 is a new disease and a lot about this disease is still unknown, and most people are afraid of the unknown. Fear is also contagious and leads to speculation. It is important to address the needs of the affected population regardless of their direct or indirect contact with the virus, race/ethnicity, age, gender, vocation, or affiliation. The spreading of clearer, more concise, and accurate information about COVID-19 would also help in reducing stigma and discrimination. ${ }^{9}$ WHO has released guidelines on how to reduce this negative stigma. First, do not attach any ethnicity or locations to the name of the disease, such as "China Virus" or "Wuhan Virus." Second, avoid referring to people with the disease with the words "victims" or "case." Third, spread accurate information about COVID-19, based on evidence. Lastly, talk positively and try to highlight the effectiveness of prevention and treatments. ${ }^{12}$

Regardless of all that is happening due to the COVID-19 pandemic, positive effects have been observed around the world. Community members worldwide have shown remarkable altruism and cooperation. Examples of community activities during COVID-19 outbreak include helping to maintain social contact with isolated people using phone calls or text messages, sharing key factual messages within communities, and providing care and support to people who have been separated from their families and caregivers. ${ }^{5}$

Amid the COVID-19 pandemic, the Indonesian government announced a policy of large-scale social restriction and urged people to work, study, pray, and basically, stay at home. ${ }^{13}$ Many people needed to adjust to this new situation. For those who have family, being at home, working, and accompanying their children in study and play at home all the time would be challenging. For others, they may also struggle to stay at home, becoming lonely, bored, and frustrated. Those who have mental health problems are more likely to experience even more difficulty. People with mental health conditions could be affected by the emotional responses brought on by the COVID-19 pandemic, resulting in relapse or worsening their existing mental health condition because of their higher susceptibility to stress compared with the general population. In addition, many people with mental health disorders need to visit their outpatient clinics for regular check-ups, medication, and psychotherapy. Under the pandemic 
and with government restrictions on staying at home and social and physical distancing, these regular visits become more difficult or improbable. Such conditions make people with mental health disorders more vulnerable to developing other mental health conditions such as anxiety, depression, substance, or behavior addiction. ${ }^{14}$ Domestic violence survivors who have to stay close to their aggressors will find the situation difficult and intimidating.

Children and adolescents who are physically active will find it difficult to confine their activities at home. Schoolwork and other extracurricular activities have been implemented online, which raises concerns on children becoming less physically active, having much longer screen time and irregular sleeping patterns, eating more unhealthy diets, and getting less social interaction with peers during the social distancing period. All of these situations will have potential effects on the physical and mental health of children, as well as on the wellbeing of the family system. ${ }^{15}$

To help promote public mental health during the COVID-19 pandemic, the Indonesian government, through the Ministry of Health, has launched Sejiwa (an abbreviation of "sehat jiwa" meaning "healthy mind") is a counseling hotline service through disaster call center 119 extension 8 to facilitate psychological consultations. ${ }^{16}$ From its launch date, April 29, 2020, until May 10, 2020, Sejiwa received 7,540 calls from the public who needed consultation regarding their psychological problems. Of that number, 6,993 have received psychological counseling from 737 volunteer psychologists from the Indonesian Psychology Association. By May 28, 2020, Sejiwa has responded to 14,916 calls across the country and has provided early psychological help to problems such as stress due to financial burdens and feeling depressed due to the large-scale social restriction. Based on the cases Sejiwa has received, the most vulnerable demographics for psychological breakdown are people of productive age, children, teenagers, and health workers. ${ }^{17,18}$

As the COVID-19 pandemic continues to affect more people worldwide, adequate support should be given to those affected by it, not only physically, but also mentally. Maintaining good mental health during the pandemic is important as it may also prevent the decline of physical health. The Indonesian Psychiatric Association (Perhimpunan Dokter Spesialis Kedokteran Jiwa Indonesia) $)^{19}$ conducted a survey on May 14, 2020, using the General Anxiety Disorder-7, Patient Health
Questionnaire-9, and Posttraumatic Stress Disorder Check List-Civilian version-17 questionnaires. The survey included 2,364 people from 34 provinces, and mostly from Jakarta, Banten, West Java, Central Java, and East Java. The data are shown on Table 1. The most common symptoms of anxiety reported by the respondents included feeling anxious that something bad will happen, worrying too much, getting angry or irritated easily, and having difficulty relaxing. Sleep problems, lack of confidence, fatigue, and loss of interest were the most prevalent complaints reported from those with depressive symptoms. ${ }^{19}$

Table 1. Psychological problems during COVID-19 in Indonesia as of May 14, 2020

\begin{tabular}{lc}
\hline Variable & $\mathrm{n}(\%)(\mathrm{N}=2,364)$ \\
\hline Psychological problems & $1,631(69)$ \\
Anxiety & $1,109(68)$ \\
Depression & $1,093(67)$ \\
Psychological trauma & $1,255(77)$ \\
\hline
\end{tabular}

COVID-19=coronavirus disease 2019

\section{How to overcome psychological stress during the COVID-19 pandemic}

The Indonesian Psychiatric Association released guidelines for the community on maintaining mental health during the COVID-19 pandemic. The guidelines were originally based on WHO guidelines, which stresses four main points in fighting stress and mass anxiety due to the COVID-19 pandemic. This recommendation has also already been proven in several studies on relieving stress. The guidelines include the following:5,19,20 (1) Limit exposure to excessive information and cut down time spent on watching, reading, or listening to news about COVID-19, including social media such as Instagram or Twitter that mostly its news do not have any proper evidence. WHO recommends checking the news only once or twice during the day. ${ }^{5}$ (2) Perform relaxation by engaging in meditation and exercise, such as physical workout, yoga, or Pilates. Getting enough rest and eating food with balanced nutrition are also important. (3) Do various activities that are relaxing and fun to vent the stress away. Looking after oneself mentally and physically during the pandemic, as well as providing a safe environment for children and the elderly, are of utmost importance. (4) During the pandemic, the community can serve as a valuable 
source of support in helping manage difficulties faced by individuals and families. Examples of support include providing education on health promotion via online media, psychological support through online communities, or psychosocial assistance for those affected by the COVID-19 pandemic. (5) Try talking and connecting with people who can be trusted about all the fears and worries that one is experiencing, which can be done through such applications as Skype or Zoom, among others. A feeling of connectedness is one of the key factors to overcoming adversities and developing resilience. Apart from promoting public education and information through social media, the Indonesian Psychiatric Association also provides counseling, which is available through their website.

For those who need to be subjected to isolation due to COVID-19 illness, Cipto Mangunkusumo Hospital developed a facility called "Pojok Sahabat," which provides a means of communication to families of COVID-19 patients. This is a collaboration among the psychiatric departments and management teams of Indonesian hospitals, together with other medical staff and volunteers. This service can accommodate up to 28 families each day, 5 days a week. This helps assuage family members who are in a constant state of worry, especially if the patients are elderly or have limited mobility and difficulty in using telecommunications devices. The patients, on the other hand, would also feel neglected and forgotten in isolation if they do not have any means of reaching out. With projects like Pojok Sahabat, family members can still communicate with patients. Furthermore, a doctor is always on call and can help explain the patient's condition to the family. The video-call technology is provided by the hospital and is connected to the isolation room. The visiting family is also accompanied by several health professionals, including a psychiatrist who can provide psychological counseling to help the family release their stress or discuss their psychological status. The psychiatrist can also assess the mental health condition of family members, as well as other psychosocial aspects, such as negative stigma toward them. In addition, the family will also be given education about COVID-19. Psychological support is needed at this moment to strengthen the patient and their family to overcome the illness because healthy mind is also important to increase their immune system. ${ }^{21}$

It is the responsibility of all stakeholders, from government, health professionals, to individuals to limit the stress, panic, and mental health impact during the pandemic. ${ }^{4}$ The form of information can be spread through YouTube, Zoom, Webinar, or other means. The government in Indonesia, already established 119 hotlines that provided information about COVID-19, however, none of this hotline provide mental health service for those who affected. Nowadays, there is an online service for mental health such as Mobile App Survey and the using of social media. In addition, to establish coordination between Indonesia and other countries in Asia, the Southeast Asia Mental Health and Counseling Association was established in collaboration with Malaysia, Brunei Darussalam, and Timor Leste. This step is expected to help Indonesia having better service for mental health aid during this pandemic. $^{22}$

\section{Conflict of Interest \\ The authors affirm no conflict of interest in this study. \\ Acknowledgment \\ None. \\ Funding Sources \\ None.}

\section{REFERENCES}

1. Khan S, Huremović D. Psychology of the pandemic. In: Huremović D, editor. Psychiatry of pandemics: a mental health response to infection outbreak. 1st ed. Cham: Springer Nature Switzerland AG; 2019. p. 37-44.

2. World Health Organization. Coronavirus disease (COVID-19) [Internet]. 2020 [cited 2020 May 26]. Available from: https:// www.who.int/indonesia/news/novel-coronavirus.

3. Williams B. Mental Health concerns arise amid COVID-19 epidemic [Internet]. New York: Psychiatry Advisor; 2020 [cited 2020 May 26]. Available from: https://www.psychiatryadvisor. com/home/topics/general-psychiatry/mental-health-concernsarise-amid-covid-19-epidemic/.

4. Centers for Disease Control and Prevention. Coronavirus disease 2019 (COVID-19): coping with stress [Internet]. 2020 [cited 2020 Apr 1]. Available from: https://www.cdc.gov/coronavirus/2019ncov/daily-life-coping/managing-stress-anxiety.html.

5. World Health Organization. Mental health and psychosocial considerations during the COVID-19 outbreak [Internet]. 2020 [cited 2020 Apr 1]. Available from: https://www.who.int/docs/ default-source/coronaviruse/mental-health-considerations.pdf.

6. Morey J, Boggero IA, Scott AB, Segerstrom SC. Current directions in stress and human immune function. Curr Opin Psychol. 2015;5:13-7.

7. Pastel RH. Collective behaviors: mass panic and outbreaks of multiple unexplained symptoms. Mil Med. 2001;166(suppl 2):44-6.

8. Pangestika D. 'We don't want people to panic': Jokowi says on lack of transparency about COVID cases [Internet]. Jakarta: The Jakarta Post; 2020 [cited 2020 May 26]. Available from: https:// www.thejakartapost.com/news/2020/03/13/we-dont-wantpeople-to-panic-jokowi-says-on-lack-of-transparency-aboutcovid-cases.html.

9. Vinkers $\mathrm{CH}$, van Amelsvoort T, Bisson JI, Branchi I, Cryan JF, Domschke $\mathrm{K}$, et al. Stress resilience during the coronavirus 
pandemic. Eur Neuropsychopharm. 2020;35:12-6.

10. Inter-Agency Standing Committee. Briefing note on addressing mental health and psychosocial aspects of COVID-19 Outbreak Version 1.1 [Internet]. 2020 [cited $2020 \mathrm{Apr}$ 1]. Available from: https://interagencystandingcommittee.org/system/ files $/ 2020-03 /$ MHPSS $\% 20$ COVID $19 \% 20$ Briefing $\% 20$ Note $\% 202 \% 20$ March\%202020-English.pdf.

11. Greenberg N, Docherty M, Gnanapragasam S, Wessely S. Managing mental health challenges faced by healthcare workers during covid-19 pandemic. BMJ. 2020;368:m1211.

12. World Health Organization. A guide to preventing and addressing social stigma associated with COVID-19 [Internet]. 2020 [cited 2020 May 26]. Available from: https://www.who.int/ who-documents-detail/a-guide-to-preventing-and-addressingsocial-stigma-associated-with-covid-19.

13. Cahya GH. Stay home, President says [Internet]. Jakarta: The Jakarta Post; 2020 [cited 2020 Apr 4]. Available from: https:// www.thejakartapost.com/news/2020/03/16/stay-homepresident-says.html.

14. Yao H, Chen JH, Xu YF. Patients with mental health disorders in the COVID-19 epidemic. Lancet Psychiat. 2020;7(4):e21.

15. Wang G, Zhang Y, Zhao J, Zhang J, Jiang F. Mitigate the effect of home confinement on children during the COVID-19 outbreak. Lancet. 2020;395:945-7.

16. The National Disaster Mitigation Agency. Call center 119 and PDSKJI official website can now serve mental health consultations [Internet]. 2020 [cited 2020 Jun 11]. Available from: https://bnpb.go.id/berita/pusat-panggilan-119-danlaman-resmi-pdskji-kini-bisa-layani-konsultasi-kesehatan-jiwa. Indonesian.

17. Anggita K. As many as 7,500 people contact Sejiwa services in 12 days [Internet]. medcom.id: Jakarta; 2020 [cited 2020 Jun 11]. Available from: https://www.medcom.id/rona/ kesehatan/ok8omxWk-sebanyak-7-500-orang-menghubungilayanan-sejiwa-dalam-12-hari. Indonesian.

18. Lestari MD. Mitigation of mental health services in the covid-19 pandemic. Presented at: Covid-19 Webinar series on social epidemiology perspectives; 2020 Jun 12; Denpasar, Indonesia. Indonesian.

19. Indonesian Psychiatric Association (PDSKJI). PDSKJI depression anxiety self-examination: psychological problems related to the COVID-19 pandemic in Indonesia [Internet]. Jakarta: Indonesian Psychiatric Association (PDSKJI); 2020 [cited 2020 May 27]. Available from: http://pdskji.org/home. Indonesian.

20. Bavel JJV, Baicker K, Boggio PS, Capraro V, Cichocka A, Cikara M, et al. Using social and behavioural science to support COVID-19 pandemic response. Nat Hum Behav. 2020;4(5):460-71.

21. MetroTV. Pojok Sahabat, covid-19 patient virtual visit facility [Internet]. 2020 [cited 2020 May 27]. Available from: https:// www.metrotvnews.com/play/ba4CVry5-pojok-sahabat-fasilitaskunjungan-virtual-pasien-covid-19. Indonesian.

22. Ifdil I, Fadli RP, Suranata K, Zola N, Ardi Z. Online mental health services in Indonesia during the COVID-19 outbreak. Asian J Psychiatr. 2020;51:102153. 